\title{
Alterações físico-químicas em morangos (Fragaria anassa Duch.) irradiados e armazenados
}

\author{
Physical-chemical alterations in irradiated and stored strawberries (Fragaria anassa Duch.)
}

\author{
Iara Luiza Tassim FRANÇOSO ${ }^{1}$, Meylene Aparecida Luzia COUTO², \\ Solange Guidolin CANNIATTI-BRAZACA ${ }^{3 *}$, Valter ARTHUR
}

\begin{abstract}
Resumo
Os morangos possuem curta vida útil pós-colheita devido à rápida deterioração causada por fungos, mesmo quando armazenados sob refrigeração. O presente trabalho teve por objetivo avaliar as alterações físico-químicas em morangos irradiados. Morangos (Fragaria anassa Duch.) da variedade Sweet Charles, colhidos na região de Valinhos-SP, foram irradiados um dia após a colheita em fonte de ${ }^{60}$ Co, nas doses de 0,5; 1,0; 1,5 e 2,0 kGy e controle, armazenados sob refrigeração $\left(4{ }^{\circ} \mathrm{C}\right)$ por 1, 8, 15, 22 e 29 dias. Para a caracterização dos frutos foi realizada a composição química. Os frutos foram avaliados quanto aos teores de sólidos solúveis totais ( ${ }^{\circ} \mathrm{Brix}$ ), acidez total titulável, pH, pectina total e solúvel nos diferentes tempos. A irradiação não provocou alterações em nenhum dos parâmetros analisados, pois não foram verificadas diferenças entre as amostras irradiadas e a controle, já entre os períodos de armazenamento ocorreram diferenças em todos os parâmetros avaliados.
\end{abstract}

Palavras-chave: morango; irradiação; armazenamento; pH; acidez total titulável.

\begin{abstract}
Strawberries have a short postharvest life due to the rapid spoilage caused by fungal infections, even when stored under refrigeration. The present research had the objective of evaluating the physical and chemical alterations in irradiated strawberries. Strawberries (Fragaria anassa Duch.) of the Sweet Charles variety, harvested in the region of Valinhos-SP, Brazil, were irradiated one day after harvest with a source of ${ }^{60} \mathrm{Co}$ in the doses of $0.5 ; 1.0 ; 1.5$ and $2.0 \mathrm{kGy}$ and control, stored under refrigeration $\left(4{ }^{\circ} \mathrm{C}\right)$ for $1,8,15,22$ and 29 days. The control sample was not submitted to irradiation. For the characterization of the fruits, the chemical composition was determined. The fruits were evaluated as to total soluble solid content ( $\left.{ }^{\circ} \mathrm{Brix}\right)$, total titrimetric acidity, $\mathrm{pH}$ and total and soluble pectin at the different time periods. Irradiation did not cause alterations in any of the parameters analyzed between irradiated samples and the control, but the periods of storage were responsible for the differences observed in all the parameters. It was concluded that the irradiation process did not change the amount of pectin, soluble solid content ( $\left.{ }^{\circ} \mathrm{Brix}\right)$, total titrimetric acidity and $\mathrm{pH}$, but storage time had an influence on these parameters.
\end{abstract}

Keywords: strawberry; irradiation; storage; $\mathrm{pH}$; total titrimetric acidity.

\section{Introdução}

As frutas constituem parte essencial na dieta equilibrada e balanceada, pois são importantes fontes de vitaminas e minerais, nutrientes indispensáveis para uma vida saudável. Dentre as frutas consumidas mundialmente, o morango encontra uma posição de destaque, sendo consumido em grande quantidade.

Em decorrência da alta produtividade e do seu gosto atrativo, o morango talvez seja considerado o fruto de maior importância entre as frutas pequenas. Apesar das dificuldades e dos riscos que envolvem a sua produção, o cultivo do morango é muito lucrativo (PADOVANI, 1991).

A rápida deterioração pós-colheita de morangos em temperatura ambiente tem sido atribuída à elevada taxa respiratória e ao aumento da produção de etileno (KADER, 1992). Outros fatores, como a suscetibilidade à lesão mecânica, a perda de água (NUNES et al., 1995) e a deterioração causada por fungos, especialmente Botrytis cinerea (PADOVANI, 1991), contribuem para diminuir o período de conservação. Além desses fatores, alterações na cor e na firmeza da polpa e a perda do brilho natural também são observadas após a colheita. Por ser um produto de alto valor comercial, principalmente no mercado in natura, o morango requer a utilização de tecnologia adequada para melhorar sua conservação.

Uma técnica que auxilia na conservação de frutas e vegetais é a irradiação, que vem sendo utilizada em diversos países.

\footnotetext{
Recebido para publicação em 23/3/2007

Aceito para publicação em 8/6/2007 (002415)

${ }^{1}$ Programa Institucional de Bolsas de Iniciação Científica - PIBIC, Escola Superior de Agricultura Luiz de Queiroz - ESALQ, Universidade de São Paulo - USP,

E-mail: francoso@esalq.usp.br

${ }^{2}$ Escola Superior de Agricultura Luiz de Queiroz - ESALQ, Universidade de São Paulo - USP, E-mail: malcouto@esalq.usp.br

${ }^{3}$ Departamento de Agroindústria, Alimentos e Nutrição, Escola Superior de Agricultura Luiz de Queiroz - ESALQ, Av. Pádua Dias, 11, CP 9, CEP 13418-900, Piracicaba- SP, Brasil, E-mail: sgcbraza@esalq.usp.br

${ }^{4}$ Laboratório de Irradiação de Alimentos e Radioentomologia, Centro de Energia Nuclear na Agricultura - CENA, Universidade de São Paulo - USP, Piracicaba - SP, Brasil, E-mail: arthur@cena.usp.br

${ }^{*}$ A quem a correspondência deve ser enviada
} 
A exposição a baixas doses de radiação pode diminuir a velocidade de amadurecimento e envelhecimento de frutas e vegetais, aumentando, desta maneira, a vida de prateleira e, conseqüentemente, as possibilidades de comercialização e maximização dos lucros tanto por parte dos produtores como por parte dos comerciantes.

Todavia, os efeitos do processo de irradiação de alimentos encontram-se em relação de estrita dependência com variáveis como a dosagem de radiação e o estágio de maturação ou de envelhecimento do alimento na época em que se realiza o tratamento (SATIN, 1993).

Pesquisas envolvendo a irradiação de alimentos têm procurado estabelecer as doses de radiação que reduzem significativamente a carga microbiana sem que ocorra o comprometimento da qualidade sensorial e nutricional do produto. Todavia, toda a eficiência do processo de irradiação depende da aplicação da dose apropriada e de sua correta aferição, a fim de se correlacionar com as análises laboratoriais (PEREIRA, 2006).

No caso particular dos morangos, para que ocorra redução significativa das infecções causadas por fungos, resultados de vários estudos indicam uma dose média de $2 \mathrm{kGy}$ e um limite máximo de $3 \mathrm{kGy}$, sendo ponto pacífico que a dose mínima para se obter resultados suficientes seria de 1,5 kGy (THOMAS, 1993). De acordo com o mesmo autor, a aplicação de doses superiores a $3 \mathrm{kGy}$ em morangos resulta em textura externa mais macia, na perda da cor rubra e na redução de outros atributos de qualidade do fruto.

O estudo realizado por D'Amour et al. (1993) indica que o amolecimento do tecido celular é um fator que limita a utilização da irradiação como método de tratamento pós-colheita. Observou-se que morangos irradiados com $4 \mathrm{kGy}$ sofreram amolecimento do tecido e parcial degradação dos polissacarídeos da parede celular, o que sinaliza que a irradiação leva a alterações químicas diferentes das quais o fruto passaria em seu processo normal de amadurecimento.

Em estudo realizado com quatro variedades de morangos tratados com radiação ionizante nas doses de 1,0; 2,0 e 3,0 kGy e armazenados por 5 e 10 dias, a uma temperatura de $6^{\circ} \mathrm{C}$, foi observado que as três variáveis examinadas (irradiação, armazenamento e variedade) afetaram significativamente as quantidades de ácido ascórbico, ácido ascórbico total e ácido dehidroascórbico nas amostras. Embora a concentração de vitamina $C$ tenha sido afetada pela irradiação em todas as variedades, esta mudança foi pequena quando comparada com a grande variação observada entre as variedades (GRAHAM; STEVENSON, 1997).

Domingues (2000), por sua vez, estudou os efeitos de tratamentos com radiação em morangos da variedade Toyonoka, combinados com dois tipos de embalagens (caixas de polietileno perfuradas, com e sem invólucro de filmes plásticos de PVC transparente), quatro doses de radiação ( 0,$0 ; 1,5 ; 2,0$ e 2,5 kGy) aplicadas um dia após a colheita, e quatro períodos de armazenamento $(1,8,15$ e 22 dia após a irradiação), a temperaturas entre 3 e $6{ }^{\circ} \mathrm{C}$ e $55 \%$ de umidade relativa. Como resultado, verificou-se que com o decorrer do tempo de armazenamento houve progressiva deterioração e perda de peso dos morangos, sendo também verificado o aumento no teor de ácido ascórbico. A utilização de embalagens com filme de PVC inibiu a desidratação dos morangos ao longo do armazenamento e reduziu o teor de sólidos solúveis das frutas armazenadas por mais de 8 dias. Ainda, os tratamentos com 2,0 e 2,5 kGy causaram perdas significativas de ácido ascórbico, sendo que a dose mais elevada também reduziu de forma significativa a textura das frutas.

O presente trabalho teve por objetivo avaliar as alterações físico-químicas nos morangos submetidos aos diferentes tratamentos de irradiação em diversos períodos de armazenamento.

\section{Material e métodos}

\subsection{Material}

Foram utilizados morangos frescos (Fragaria anassa Duch.), cv. Sweet Charles, cultivados em Valinhos-SP, os quais foram colhidos, selecionados, embalados em caixas plásticas perfuradas e transportados no mesmo dia para o Laboratório de Bromatologia para o preparo das amostras. Essa cultivar tem excelentes características para consumo in natura e boa aceitação no mercado.

\subsection{Métodos}

\section{Preparo das amostras}

Os frutos foram pesados em balança Tecnal modelo B-TEC 2200 e separados em embalagens contendo aproximadamente $200 \mathrm{~g}$, totalizando 30 embalagens, e em seguida foram levados ao Laboratório de Irradiação de Alimentos e Radioentomologia do Centro de Energia Nuclear na Agricultura - CENA/USP. As amostras foram irradiadas utilizando-se fonte de ${ }^{60} \mathrm{Co}$ em irradiador tipo Gammacell-220 fabricado por Atomic Energy of Canadá Limited (AECL) Ottawa, Ontario, Canadá, MDS Nordion 1989, 52,2 TBq (1.519,06 Ci). Foram utilizados 5 tratamentos, sendo eles controle (não irradiado - T1) e tratamentos com irradiação nas doses de 0,5 ; 1,0; 1,5 e 2,0 kGy, sendo respectivamente T2, T3, T4 e T5. Os diferentes tratamentos foram avaliados em cinco períodos de armazenamento (1, 8, 15, 22 e 29 dia após a irradiação).

As amostras, após serem irradiadas, foram armazenadas e mantidas refrigeradas à temperatura de $4{ }^{\circ} \mathrm{C}$.

\section{Composição centesimal}

A composição centesimal foi realizada com o objetivo de caracterizar a amostra utilizada. As análises de umidade, cinzas, extrato etéreo e proteína foram realizadas de acordo com a metodologia descrita pela AOAC (2005), sendo os carboidratos totais determinados por diferença.

\section{Minerais}

Para a determinação dos minerais seguiu-se metodologia de Sarruge e Haag (1974). Foi adicionado ácido nítrico concentrado nas amostras e essas foram deixadas em repouso durante 
12 horas, em seguida foram colocadas em bloco digestor marca Sarge até que atingissem a temperatura de $150^{\circ} \mathrm{C}$ e o volume fosse reduzido à metade. Adicionou-se posteriormente ácido perclórico concentrado e a temperatura foi elevada gradativamente até atingir $250{ }^{\circ} \mathrm{C}$. Após o resfriamento, o material foi diluído em água deionizada e feita a leitura em espectrofotômetro de absorção atômica, modelo PERKIM-ELMER, modelo 3.110.

\section{Sólidos solúveis e pH}

Para a determinação de tais parâmetros foram utilizadas amostras de cada tratamento, as quais foram liquefeitas e homogeneizadas antes da realização das medidas. As amostras foram analisadas, quanto aos sólidos solúveis totais, expressos em graus ${ }^{\circ}$ Brix, que foram determinados em refratômetro $\mathrm{ABBE}$ tipo WYA, e corrigidos em relação à temperatura. $\mathrm{O} \mathrm{pH}$ foi medido em pHmetro digital de bancada marca Tecnopon modelo $m$ PA-210/mPA210P, segundo metodologia indicada pela AOAC (2005).

\section{Acidez total titulável}

A acidez total titulável foi determinada com $\mathrm{NaOH} 0,1 \mathrm{~N}$, utilizando a fenolftaleína como indicador. Para cada amostra foram consideradas três repetições, utilizando-se as médias como resultados, estes foram expressos em miligramas de ácido cítrico por $100 \mathrm{~g}$ de polpa de morango, de acordo com as normas do Instituto Adolfo Lutz (PREGNOLATTO, 1985).

\section{Pectinas}

As pectinas totais e solúveis do fruto foram extraídas segundo a técnica padronizada por McCready e McComb (1952). Na dosagem foi utilizada a técnica de Bitter e Muir (1962), e os resultados expressos em mg de ácido galacturônico por $100 \mathrm{~g}$ de peso fresco.

\section{Análise estatística}

Os dados obtidos foram submetidos à análise de variância (ANOVA). Para verificar quais tratamentos diferiram, foi aplicado o teste de Tukey para realizar comparações pareadas das médias dos tratamentos, estabelecendo-se o nível mínimo de significância de 5\% ( $\leq 50,05)$. Utilizou-se o software SAS Institute (1999).

\section{Resultados e discussão}

\subsection{Composição centesimal e minerais}

$\mathrm{Na}$ Tabela 1 podemos observar os valores da composição centesimal e dos teores de minerais presentes nos morangos utilizados.

De acordo com os dados da tabela de composição química dos alimentos (USDA, 2006), a quantidade de proteínas em morangos é 0,67 g por $100 \mathrm{~g}$ de polpa; o teor de extrato etéreo é de $0,3 \mathrm{~g}$ por $100 \mathrm{~g}$, o mesmo valor encontrado na Tabela Brasileira de Composição de Alimentos (UNICAMP, 2006); e o de cinzas é 0,4 g por $100 \mathrm{~g}$ (USDA, 2006), inferior ao
Tabela 1. Composição centesimal (g.100 g $\left.{ }^{-1}\right)$ e mineral (mg.100 g $\left.{ }^{-1}\right)$ dos frutos utilizados.

\begin{tabular}{lr}
\hline \multicolumn{2}{c}{ Composição química dos morangos } \\
\hline Proteínas $\left(\mathrm{g} \cdot 100 \mathrm{~g}^{-1}\right)$ & $0,78 \pm 0,00^{1}$ \\
Extrato etéreo $\left(\mathrm{g} \cdot 100 \mathrm{~g}^{-1}\right)$ & $0,20 \pm 0,03$ \\
Umidade $\left(\mathrm{g} \cdot 100 \mathrm{~g}^{-1}\right)$ & $93,08 \pm 0,02$ \\
Cinzas $\left(\mathrm{g} \cdot 100 \mathrm{~g}^{-1}\right)$ & $0,44 \pm 0,08$ \\
Carboidratos totais $\left(\mathrm{g} \cdot 100 \mathrm{~g}^{-1}\right)$ & $5,50 \pm 0,05$ \\
$\mathrm{Zn}\left(\mathrm{mg} \cdot 100 \mathrm{~g}^{-1}\right)$ & $0,01 \pm 0,00$ \\
$\mathrm{Ca}\left(\mathrm{mg} \cdot 100 \mathrm{~g}^{-1}\right)$ & $19,80 \pm 0,92$ \\
$\mathrm{~K}\left(\mathrm{mg} \cdot 100 \mathrm{~g}^{-1}\right)$ & $18,63 \pm 2,32$ \\
$\mathrm{Mg}\left(\mathrm{mg} \cdot 100 \mathrm{~g}^{-1}\right)$ & $12,28 \pm 0,53$ \\
$\mathrm{Na}\left(\mathrm{mg} \cdot 100 \mathrm{~g}^{-1}\right)$ & $21,95 \pm 4,88$ \\
$\mathrm{Cu}\left(\mathrm{mg} \cdot 100 \mathrm{~g}^{-1}\right)$ & $0,03 \pm 0,01$ \\
$\mathrm{Fe}\left(\mathrm{mg} \cdot 100 \mathrm{~g}^{-1}\right)$ & $0,23 \pm 0,30$ \\
$\mathrm{P}\left(\mathrm{mg} \cdot 100 \mathrm{~g}^{-1}\right)$ & $35,12 \pm 0,74$ \\
$\mathrm{Mn}\left(\mathrm{mg} \cdot 100 \mathrm{~g}^{-1}\right)$ & $0,06 \pm 0,00$ \\
\hline
\end{tabular}

${ }^{1}$ Médias de três repetições \pm desvio padrão.

valor de 0,5 g (UNICAMP, 2006). Ainda, o teor de carboidratos é de 6,8 g. $100 \mathrm{~g}^{-1}$, de acordo com a Unicamp (2006) e 7,68 g. $100 \mathrm{~g}^{-1}$ conforme descrito pela USDA (2006).

Como pode ser observado na Tabela 1 , a quantidade média de proteína encontrada nas amostras $\left(0,78 \mathrm{~g} .100 \mathrm{~g}^{-1}\right)$ é superior ao valor descrito pela USDA (2006), o valor de extrato etéreo encontrado está de acordo com a literatura, assim como a quantidade de cinzas e carboidratos. $\mathrm{O}$ teor de umidade obtido, 93,08\%, está de acordo com o encontrado por Condenunsi et al. (2002).

Comparando-se os valores de minerais encontrados nesse experimento (Tabela 1), com os dados da Tabela Brasileira de Composição de Alimentos (UNICAMP, 2006) e com os da Tabela de Composição Química de Alimentos (USDA, 2006) constatou-se que as quantidades de ferro, cobre e magnésio estão de acordo com a literatura; as de manganês, zinco e potássio são inferiores, já as quantidades de fósforo, cálcio e sódio encontradas foram superiores às descritas na literatura. As discrepâncias observadas podem ocorrer devido, principalmente, às diferenças entre as cultivares analisadas e os tratos culturais.

\subsection{Sólidos solúveis}

Os dados obtidos para o teor de sólidos solúveis, entre 7,0 a $9,5^{\circ}$ Brix, dispostos na Tabela 2, estão de acordo com o resultado encontrado por Mosca et al. (2001). Os valores determinados por Domingues (2000) indicam que a variedade Sweet Charles utilizada nesse experimento é menos doce que a variedade Toyonoka, 9,07 a 10,60 ${ }^{\circ} \mathrm{Brix}$, e mais doce que as variedades Dover e Campineiro, 5,4 e 6,0 ${ }^{\circ} \mathrm{Brix}$, respectivamente, valores determinados por Cordenunsi et al. (2002), pois o teor de sólidos solúveis nos dá um indicativo da quantidade de açúcares existentes na fruta, considerando que outros compostos, em menores proporções, como os ácidos, as vitaminas, os aminoácidos e algumas pectinas, também fazem parte da composição dos sólidos solúveis da fruta (KLUGE et al., 2002). Usualmente eles 
aumentam no transcorrer do processo de maturação da fruta, seja por biossíntese ou pela degradação de polissacarídeos.

O período de armazenamento afetou de maneira significativa o teor de sólidos solúveis totais dos frutos, como podemos observar na Tabela 2. Scalon et al. (1996) também observaram decréscimo deste teor durante o período de armazenamento, diferente do resultado encontrado por Domingues (2000), no qual houve aumento dos sólidos solúveis nas amostras irradiadas e não embaladas com filme plástico, já nas amostras com o filme houve decréscimo. De acordo com Kluge et al. (2002), após o armazenamento prolongado o teor de açúcares decresce.

Observando-se os dados obtidos, podemos constatar que os diferentes tratamentos não provocaram alteração nos teores de sólidos solúveis totais, uma vez que não ocorreram diferenças significativas $(p>0,05)$ entre as amostras. Sendo assim, verifica-se que a irradiação não teve efeito sobre os sólidos solúveis totais, pois as amostras irradiadas não diferiram da amostra controle.

\section{$3.3 \mathrm{pH}$}

Com relação aos valores obtidos para $\mathrm{pH}$, como pode ser observado na Tabela 3, entre 3,30 e 3,62, esses estão de acordo com o valor de 3,6 encontrado por Mosca et al. (2001) e aos valores de 3,53 a 3,69 descritos por Domingues (2000).

Através da observação dos dados da Tabela 3, verifica-se que ocorreram diferenças significativas $(p>0,05)$ entre as amostras nos diferentes períodos de armazenamento. $\mathrm{O}$ mesmo foi observado por Bicalho (1998) ao final do período de armazenamento de mamão.

Tabela 2. Teor de sólidos solúveis ( ${ }^{\circ}$ Brix) nos tratamentos nos diferentes tempos.

\begin{tabular}{lcccccc}
\hline \multirow{2}{*}{ Tratamento } & \multicolumn{5}{c}{ Dias } & \multirow{2}{*}{ Média } \\
\cline { 2 - 5 } & 1 & 8 & 15 & 22 & 29 & \\
\hline Controle & $9,00^{1}$ & 8,00 & 7,50 & 7,80 & 7,50 & $7,96^{\mathrm{A}}$ \\
$0,5 \mathrm{kGy}$ & 7,00 & 9,00 & 9,00 & 8,80 & 7,80 & $8,32^{\mathrm{A}}$ \\
$1,0 \mathrm{kGy}$ & 9,50 & 9,25 & 8,25 & 8,30 & 7,50 & $8,56^{\mathrm{A}}$ \\
$1,5 \mathrm{kGy}$ & 9,00 & 9,00 & 8,75 & 8,50 & 7,00 & $8,45^{\mathrm{A}}$ \\
$2,0 \mathrm{kGy}$ & 8,00 & 9,25 & 8,75 & 9,20 & 7,00 & $8,44^{\mathrm{A}}$ \\
Média & $8,5^{\text {ba }}$ & $8,9^{\mathrm{a}}$ & $8,45^{\mathrm{ba}}$ & $8,52^{\text {ba }}$ & $7,36^{\mathrm{b}}$ & - \\
\hline
\end{tabular}

${ }^{1}$ Valores com letras maiúscula(s) diferente(s) na vertical diferem estatisticamente a $5 \%$ de significância; $e^{2}$ valores com letras minúscula(s) diferente(s) na horizontal diferem estatisticamente a $5 \%$ de significância.

Tabela 3. Valores de $\mathrm{pH}$ ao longo de cinco períodos nos diferentes tratamentos.

\begin{tabular}{cllllll}
\hline Tratamento & \multicolumn{5}{c}{ Dias } & Média \\
\cline { 2 - 5 } & \multicolumn{1}{c}{1} & 8 & 15 & 22 & 29 & \\
\hline Controle & 3,381 & 3,36 & 3,42 & 3,40 & 3,54 & $3,42^{\mathrm{A}}$ \\
$0,5 \mathrm{kGy}$ & 3,33 & 3,39 & 3,49 & 3,45 & 3,50 & $3,41^{\mathrm{A}}$ \\
$1,0 \mathrm{kGy}$ & 3,30 & 3,36 & 3,32 & 3,30 & 3,46 & $3,35^{\mathrm{A}}$ \\
$1,5 \mathrm{kGy}$ & 3,38 & 3,37 & 3,40 & 3,41 & 3,42 & $3,40^{\mathrm{A}}$ \\
$2,0 \mathrm{kGy}$ & 3,37 & 3,41 & 3,48 & 3,43 & 3,62 & $3,46^{\mathrm{A}}$ \\
Média & $3,35^{\mathrm{b} 2}$ & $3,38^{\mathrm{b}}$ & $3,42^{\text {ba }}$ & $3,39^{\mathrm{b}}$ & $3,51^{\mathrm{a}}$ & - \\
\hline
\end{tabular}

${ }^{1}$ Valores com letras maiúscula(s) diferente(s) na vertical diferem estatisticamente a $5 \%$ de significância; $e^{2}$ valores com letras minúscula(s) diferente(s) na horizontal diferem estatisticamente a $5 \%$ de significância.
Quanto aos diferentes tratamentos, podemos constatar que não ocorreram diferenças significativas entre a amostra controle e as amostras submetidas às diferentes doses de irradiação. Esses dados revelam que a radiação aplicada não interfere no comportamento do $\mathrm{pH}$ dos morangos, uma vez que o tratamento testemunha (sem irradiação) teve comportamento semelhante aos demais.

\subsection{Acidez total titulável}

Os ácidos orgânicos presentes nos frutos, em balanço com os teores de açúcares, representam um importante atributo de qualidade. Muitos desses ácidos são voláteis, contribuindo dessa forma para o aroma característico das frutas (KLUGE et al., 2002; BLEINROTH, 1986).

Os valores de acidez total titulável (mg.100 $\mathrm{g}^{-1}$ de polpa) obtidos (Tabela 4), entre 1,14 e 1,68, são superiores aos descritos na literatura por Domingues (2000), entre 0,85 e 0,99 mg. $100 \mathrm{~g}^{-1}$, no entanto, as discrepâncias observadas podem ser devido às diferenças entre as cultivares.

De acordo com os dados dispostos na Tabela 4, constatou-se que as diferentes doses aplicadas não ocasionaram alterações significativas $(p>0,05)$ nas amostras. Ainda, observou-se que o período de armazenamento apresentou diferenças significativas ( $\mathrm{p} \leq 0,05)$ na acidez total titulável dos frutos. De acordo com Calegano, Pezzi e Bender (2002), os ácidos orgânicos tendem a diminuir durante o amadurecimento dos frutos, em virtude de sua utilização como substrato respiratório, sendo assim, evidencia-se o fato da irradiação não ter tido efeito sobre a acidez total titulável, uma vez que não alterou o comportamento normal dos frutos durante o amadurecimento.

\subsection{Pectinas}

O valor médio de pectina solúvel encontrado no experimento (Tabela 5), 590,71 mg de ácido galacturônico por $100 \mathrm{~g}$ de amostra fresca, é superior ao encontrado por Contreras et al. (2007), que encontraram o valor de $150 \mathrm{~g} .100 \mathrm{~g}^{-1}$, e inferior ao descrito por Yu, Reitmier e Love (1996), que encontraram valores de 4,46 5,15\% e D’Amour et al. (1993), que encontraram valores de 25,5 a 25,9\% em relação à parede celular em ambos os estudos.

O período de armazenamento mostra diferença estatística $(\mathrm{p} \leq 0,05)$ na concentração de pectina solúvel dos frutos, conforme valores apresentados na Tabela 5, pois as substâncias pécticas são os principais componentes químicos dos tecidos responsáveis pelas mudanças de textura dos frutos e hortaliças. Quando os grupos carboxílicos ácidos encontram-se ligados ao cálcio, formam o pectato de cálcio, que é insolúvel e também designado como protopectina, predominante em frutas imaturas. Com o amadurecimento, há liberação de cálcio e solubilização de protopectina das paredes celulares, por ação enzimática. Há então modificação da textura, que se torna gradualmente macia. Essas transformações ocorrem não só durante o amadurecimento, como também no armazenamento de frutos e algumas hortaliças. As pectinas em frutos encontram-se sob diferentes formas, caracterizadas por diferentes solubilidades. A protopectina é uma forma insolúvel em água e que, por hidrólise parcial, 
produz ácidos pectínicos ou ácidos pécticos, também chamados de pectinas solúveis (CHITARRA; CHITARRA, 1990).

Observando-se os dados da Tabela 5 pode-se constatar que a irradiação não provocou alterações no comportamento das pectinas solúveis nos morangos analisados, uma vez que as amostras irradiadas apresentaram o mesmo comportamento da amostra controle.

Quanto aos períodos de armazenamento ocorreu diferença estatística na concentração de pectina solúvel (Tabela 5).

O valor médio de pectina total observado, 754,64 mg. $100 \mathrm{~g}^{-1}$, disposto na Tabela 6, foi superior ao valor encontrado por Contreras et al. (2007), os quais encontraram $530 \mathrm{mg} .100 \mathrm{~g}^{-1} \mathrm{e}$ inferior ao encontrado por Yu, Reitmeier e Love (1996) com valores de 18,43 a 20,38\% em relação à parede celular.

Assim como foi observado na Tabela 5, a irradiação não provocou alterações no comportamento da pectina total nas amostras de morango, uma vez que não foram observadas diferenças significativas entre as amostras nos diferentes tratamentos. Já quanto aos períodos de armazenamento, constatou-se que houve diferença significativa no teor de pectina total dos frutos. Belli-Donini e Stornaiuolo (1969) observaram que os valores de pectina diminuíram durante o armazenamento, e ainda, que as amostras irradiadas apresentaram maiores valores que a amostra controle.

\section{Conclusões}

Nas condições em que os experimentos foram realizados, pode-se concluir que:

- A irradiação não provocou mudanças nos valores de $\mathrm{pH},{ }^{\circ}$ Brix, acidez titulável, pectina total e solúvel, pois não foram verificadas diferenças entre o controle e as amostras submetidas às diferentes doses de irradiação; e

- Os períodos de armazenamento foram os responsáveis pelas diferenças observadas em todos os parâmetros, sendo assim, conclui-se que os frutos tiveram comportamentos iguais aos esperados, já que durante o período de amadurecimento e senescência ocorrem alterações nas composições físico-químicas da maioria dos frutos.

Tabela 4. Resultados de acidez total titulável $\left(\mathrm{mg} .100 \mathrm{~g}^{-1}\right)$ dos diferentes tratamentos e tempos.

\begin{tabular}{|c|c|c|c|c|c|c|}
\hline \multirow[t]{2}{*}{ Tratamento } & \multicolumn{5}{|c|}{ Dias } & \multirow[t]{2}{*}{ Médiz } \\
\hline & 1 & 8 & 15 & 22 & 29 & \\
\hline Controle & $1,34 \pm 0,2^{1}$ & $1,34 \pm 0,2$ & $1,34 \pm 0,1$ & $1,41 \pm 0,0$ & $1,14 \pm 0,1$ & $1,31^{2 \mathrm{~A}}$ \\
\hline 0,5 kGy & $1,48 \pm 0,1$ & $1,27 \pm 0,1$ & $1,21 \pm 0,0$ & $1,34 \pm 0,1$ & $1,14 \pm 0,1$ & $1,29^{\mathrm{A}}$ \\
\hline 1,0 kGy & $1,61 \pm 0,2$ & $1,27 \pm 0,2$ & $1,27 \pm 0,0$ & $1,68 \pm 0,1$ & $1,24 \pm 0,1$ & $1,41^{\mathrm{A}}$ \\
\hline 1,5 kGy & $1,48 \pm 0,1$ & $1,21 \pm 0,2$ & $1,41 \pm 0,0$ & $1,48 \pm 0,1$ & $1,24 \pm 0,1$ & $1,36^{\mathrm{A}}$ \\
\hline 2,0 kGy & $1,48 \pm 0,1$ & $1,21 \pm 0,0$ & $1,41 \pm 0,0$ & $1,48 \pm 0,1$ & $1,17 \pm 0,1$ & $1,35^{\mathrm{A}}$ \\
\hline
\end{tabular}

${ }^{1}$ Médias de três repetições; ${ }^{2}$ médias com letras maiúscula(s) diferente(s) na vertical diferem estatisticamente a $5 \%$ de significância; e ${ }^{3}$ médias com letras minúscula(s) diferente(s) na horizontal diferem estatisticamente a $5 \%$ de significância.

Tabela 5. Valores de pectina solúvel $\left(\mathrm{mg} .100 \mathrm{~g}^{-1}\right)$ nas amostras nos diferentes tratamentos e tempos.

\begin{tabular}{|c|c|c|c|c|c|c|}
\hline \multirow[t]{2}{*}{ Tratamento } & \multicolumn{5}{|c|}{ Dias } & \multirow{2}{*}{ Média } \\
\hline & 1 & 8 & 15 & 22 & 29 & \\
\hline Controle & $665,76 \pm 55,7^{1}$ & $669,96 \pm 20,7$ & $617,27 \pm 16,7$ & $617,49 \pm 33,8$ & $642,97 \pm 51,0$ & $642,69^{\mathrm{A} 2}$ \\
\hline $0,5 \mathrm{kGy}$ & $591,90 \pm 43,4$ & $707,06 \pm 56,4$ & $712,31 \pm 10,7$ & $565,71 \pm 84,1$ & $697,68 \pm 57,5$ & $654,93^{\mathrm{A}}$ \\
\hline $1,0 \mathrm{kGy}$ & $565,29 \pm 14,7$ & $818,38 \pm 79,8$ & $637,79 \pm 3,3$ & $676,96 \pm 18,8$ & $697,64 \pm 76,7$ & $679,21^{\mathrm{A}}$ \\
\hline 1,5 kGy & $507,01 \pm 28,9$ & $832,73 \pm 86,0$ & $635,86 \pm 4,3$ & $685,95 \pm 43,2$ & $680,00 \pm 48,7$ & $668,31^{\mathrm{A}}$ \\
\hline 2,0 kGy & $542,71 \pm 15,2$ & $830,63 \pm 47,3$ & $688,02 \pm 3,3$ & $722,85 \pm 14,1$ & $706,78 \pm 70,8$ & $698,10^{\mathrm{A}}$ \\
\hline Média & $574,53^{\mathrm{c} 3}$ & $771,75^{\mathrm{a}}$ & $658,25^{\mathrm{bc}}$ & $653,79^{\mathrm{bc}}$ & $685,02^{\text {ba }}$ & - \\
\hline
\end{tabular}

${ }^{1}$ Médias de três repetições; ${ }^{2}$ médias com letras maiúscula(s) diferente(s) na vertical diferem estatisticamente a $5 \%$ de significância; e ${ }^{3}$ médias com letras minúscula(s) diferente(s) na horizontal diferem estatisticamente a $5 \%$ de significância.

Tabela 6. Valores de pectina total $\left(\mathrm{mg} 100 \mathrm{~g}^{-1}\right)$ nas amostras nos diferentes tratamentos e tempos.

\begin{tabular}{|c|c|c|c|c|c|c|}
\hline \multirow[t]{2}{*}{ Tratamento } & \multicolumn{5}{|c|}{ Dias } & \multirow[t]{2}{*}{ Média } \\
\hline & 1 & 8 & 15 & 22 & 29 & \\
\hline Controle & $759,50 \pm 3,2^{1}$ & $1611,01 \pm 96,5$ & $789,78 \pm 72,3$ & $1210,28 \pm 48,8$ & $1671,70 \pm 40,0$ & $1208,5^{\mathrm{A} 2}$ \\
\hline 0,5 kGy & $757,75 \pm 5,0$ & $1316,09 \pm 63,0$ & $800,72 \pm 6,6$ & $1705,61 \pm 66,3$ & $2016,67 \pm 35,0$ & $1332,7^{\mathrm{A}}$ \\
\hline $1,0 \mathrm{kGy}$ & $748,48 \pm 3,8$ & $1610,13 \pm 88,2$ & $746,81 \pm 2,8$ & $1352,56 \pm 1,3$ & $2119,33 \pm 68,9$ & $1329,2^{\mathrm{A}}$ \\
\hline 1,5 kGy & $751,98 \pm 6,2$ & $1616,70 \pm 64,3$ & $775,60 \pm 5,6$ & $1328,43 \pm 28,9$ & $1615,73 \pm 54,7$ & $1202,2^{\mathrm{A}}$ \\
\hline 2,0 kGy & $755,48 \pm 9,3$ & $1304,30 \pm 45,9$ & $962,97 \pm 1,6$ & $1226,47 \pm 10,2$ & $1717,38 \pm 43,9$ & $1207,9^{\mathrm{A}}$ \\
\hline
\end{tabular}

${ }^{1}$ Médias de três repetições; ${ }^{2}$ médias com letras maiúscula(s) diferente(s) na vertical diferem estatisticamente a $5 \%$ de significância; e ${ }^{3}$ médias com letras minúscula(s) diferente(s) na horizontal diferem estatisticamente a $5 \%$ de significância. 


\section{Agradecimentos}

Ao prof. Keigo Minami pela disponibilidade e indicação de produtores, à produtora que doou as amostras e à técnica do Laboratório de Bromatologia e Nutrição experimental, Débora Niero Mansi, pelo auxílio na realização das análises químicas.

\section{Referências bibliográficas}

AOAC - ASSOCIATION OF OFFICIAL ANALYTICAL CHEMISTS. Official Method of Analysis. 18 ed. Washington, DC, USA, 2005.

BELLI-DONINI, M.; STORNAIUOLO, M. R. Pectin changes in the ripening of irradiated and stored strawberries. Journal of Food Science, v. 34, n. 6, p. 509-514, 1969.

BICALHO, U. O. Vida útil pós-colheita de mamão submetido a tratamento com cálcio e filme de PVC. Lavras, 1998. 154p. Tese - (Doutorado em Ciência dos Alimentos), Universidade Federal de Lavras.

BITTER, V.; MUIR, H. M. A modified uronic acid carbazole reaction. Analitical Biochemistry, v. 34, n. 4, p. 330-334, 1962.

BLEINROTH, E. W. Colheita, embalagem e conservação. In: Simpósio sobre a cultura do morangueiro, 1. Cabreúva-SP. A Cultura do morangueiro. Jaboticabal: UNESP, FCAV, 1986. p. 1-14. cap.1.

CALEGANO, J. M.; PEZZI, E.; BENDER, R. J. Utilização de atmosfera modificada na conservação de morangos em pós-colheita. Pesquisa Agropecuária Brasileira, v. 37, n. 8, p. 1049-1055, 2002.

CHITARrA, M. I. F.; CHITARRA, A. B. Pós-colheita de frutos e hortaliças: fisiologia e manuseio. Lavras: ESAL/FAEPE, 1990. 320 .

CONTRERAS, C. et al. Influence of osmotic pre-treatment and microwave application on properties of air dried strawberry related to structural changes. European Food Research and Technology, v. 224, n. 4, p. 499-504, 2007.

CORDENUNSI, B. R. et al. Influence of cultivar on quality parameters and chemical composition of strawberry fruits grown in Brazil. Journal of Agricultural and Food Chemistry, v. 50, n. 9, p. 2581-2586, 2002.

D'AMOUR, J. et al. Gamma-radiation affects cell wall composition of strawberries. Journal of Food Science, v. 58, n. 1, p. 182-185, 1993.

DOMINGUES, D. M. Efeito da radiação gama e embalagem na conservação de morangos "Toyonoka" armazenados sob refrigeração. Piracicaba, 2000. 58p. Dissertação - (Mestrado em Energia Nuclear na Agricultura), Escola Superior de Agricultura "Luiz de Queiroz", Universidade de São Paulo.

GRAHAM, W. D.; STEVENSON, M.H. Effect of irradiation on vitamin $\mathrm{C}$ content of strawberries and potatoes in combination with storage and with further cooking in potatoes. Journal of the Science of Food and Agriculture, v. 75, n. 3, p. 371-377, 1997.

KADER, A. A. Postharvest technology of horticultural crops. 2 ed. Oakland: University of California, 1992. 296p.

KLUGE, R. A. et al. Fisiologia e manejo pós-colheita de frutas de clima temperado. Livraria e Editora Rural. 2 ed. Campinas, 2002. $214 \mathrm{p}$.

McCREAD, P. M.; MCCOMB, E. A. Extraction and determination of total pectin materials. Analitical Chemistry, v. 24, n. 12, p. 1586-1588, 1952.

MOSCA, J. L. et al. Avaliação fisico-química e sensorial de morango das cultivares Toyonoka e Sweet Charlie. In: CONGRESSOS BRASILEIROS DE OLERICULTURA, 41, 2001, Brasília - DF. Anais... Brasília, p. 236, 2001.

NUNES, M. C. N. et al. Physical and chemical quality characteristics of strawberries after storage are reduced by a short delay to cooling. Postharvest Biology and Technology, v. 6, n. 1, p. 17-28, 1995.

PADOVANI, M. I. Morango: o delicado e saboroso fruto da integração dos povos. São Paulo: Ícone, 1991. 68p. (Coleção Brasil Agrícola).

PEREIRA, A. S. C. Irradiação em Alimentos. Disponível em: <http:// www.dipemar.com.br/CARNE/324/materia_pesquisa_carne.htm>. Acesso em: 23 de Jan. 2006.

PREGNOLATTO, W. Normas analíticas do Instituto Adolfo Lutz: métodos químico-físicos para análise de alimentos. 3 ed. São Paulo: Instituto Adolfo Lutz, 1985. v. 2.

SARRUGE, J. R.; HAAG, H. P. Análises químicas em plantas. Piracicaba: ESALQ/USP, 1974. p. 56.

SAS INSTITUTE. SAS user's guide: statistics. Version 8.0. Cary: SAS, 1999.

SATIN, M. Food Irradiation: a guidebook. Lancaster: Technomic Publishing, 1993. 183p.

SCALON, S. P. Q. et al. Conservação de morangos (Fragaria. ananassa Duch.) cv. Sequóia em atmosfera modificada. Revista Brasileira de Fruticultura, v. 18, n. 3, p. 431-436, 1996.

THOMAS, P. Irradiation of strawberries: a compilation of technical data for its authorization and control. In: MEETING OF THE INTERNATIONAL CONSULTATIVE GROUP OF FOOD IRRADIATION (ICGFI), 10. Geneva: WHO, 1993. 37p.

UNICAMP - Universidade Estadual de Campinas. Tabela brasileira de composição de alimentos. Disponível em: <http://www.unicamp. br/nepa/taco/contar/taco_versao2.pdf > Acesso em: 10 fev. 2006.

USDA - United States Department of Agriculture. Tabela de composição química de alimentos. Disponível em: <http: //www.unifesp.br/dis/ servicos/nutri/nutri.php?id=2245>. Acesso em: 10 de fev. 2006.

YU, L.; REITMEIER, C. A.; LOVE, M. H. Strawberry texture and pectin content as affected by electrom beam irradiation. Journal of Food Science, v. 61, n. 4, p. 844-846, 1996. 